\title{
A LIDERANÇA COMO ELEMENTO DO COMPORTAMENTO EMPREENDEDOR: UM ESTUDO EXPLORATÓRIO
}

\section{THE LEADERSHIP AS ELEMENT OF THE ENTREPRENEURIAL BEHAVIOR: AN EXPLORATORY STUDY}

\author{
ÁLVARO CARDOSO ARMOND \\ Mestre em Administração pela Universidade Presbiteriana Mackenzie (UPM). \\ Professor do Programa de Pós-Graduação em Administração do Insper Instituto de Ensino e Pesquisa. \\ Rua Volta Redonda, 598, Campo Belo - São Paulo - SP - Brasil - CEP 04608-01 1 \\ E-mail: acarmond@uol.com.br \\ VANIIA MARIA JORGE NASSIF \\ Doutora em Administração pela Universidade Presbiteriana Mackenzie (UPM). \\ Professora e coordenadora do Núcleo de Empreendedorismo e \\ Desenvolvimento Empresarial da Universidade Presbiteriana Mackenzie. \\ Rua Major Sertório, 733, Vila Buarque - São Paulo - SP - Brasil - CEP 01222-010 \\ E-mail:vania.nassif@uol.com.br
}




\section{RESUMO}

Parece haver consenso sobre o fato de que o elemento central do empreendedorismo é o empreendedor. Foi com base nessa premissa que o presente estudo desenvolveu-se. Realizou-se pesquisa para identificar os comportamentos de liderança adotados pelos empreendedores para promover as mudanças organizacionais requeridas para consolidar e desenvolver seus empreendimentos. A pesquisa é de natureza qualitativa e exploratória, tendo sido realizada por meio de entrevistas em profundidade, com três empreendedores, que geraram cerca de quatro horas de relatos com cada um deles. Encontraram-se evidências de que os comportamentos de liderança adotados pelos empreendedores, visando ao crescimento de suas organizações, estão alinhados com o referencial teórico estudado, especialmente no que se refere às ações orientadas ao relacionamento e à mudança. Depreende-se que, embora as experiências relatadas apresentem convergência com os pressupostos teóricos, há nuanças pessoais e contextuais significativas que caracterizariam, assim, a liderança como um exercício individual, mediado por fatores ambientais específicos.

\section{PALAVRAS-CHAVE}

Empreendedorismo; Empreendedor; Comportamento; Liderança; Mudança organizacional.

\section{ABSTRACT}

It seems there is an agreement about the fact that the central element of the entrepreneurship is the entrepreneur. This was the assumption used in this study. A survey was carried out to identify the leadership behaviors applied by entrepreneurs in order to promote the organizational changes required to consolidate and develop their businesses. The survey was qualitative and exploratory, developed though in-depth interviews with three entrepreneurs, that generate four hours of report from each one of 
them. Evidences were found that the leadership behaviors applied by entrepreneurs in order to promote the growth of their ventures are consistent with the theory, particularly with respect to relationship and change. Hence, it's possible to presume that, although the experiences narrated here are aligned with the theory, there are some significant personal and contextual aspects which would characterize leadership as an individual exercise, mediated by specific environmental factors.

\section{KEYWORDS}

Entrepreneurship; Entrepreneur; Behavior; Leadership; Organizational change.

\section{INTRODUÇÃO}

O tema empreendedorismo tem despertado o interesse nos meios acadêmicos há muito tempo. Desde os primeiros trabalhos de Richard Cantillon, escritos em I725, passando pelas contribuições marcantes de Jean Baptiste Say, em I803, Francis Walker, em I876, e Joseph Schumpeter, em I934, até as obras contemporâneas de McClelland, Drucker, Pinchot, Morris, Kuratko e Hisrich, consideráveis avanços foram obtidos e um ambiente de saudável controvérsia e embate acadêmico tem proliferado. Um dos aspectos mais presentes no centro das discussões sobre empreendedorismo é o papel do indivíduo no processo empreendedor, ou, de forma mais objetiva, o papel do empreendedor no âmbito do empreendedorismo. Cuff (2002, p. I23), em "Notes for a panel on entrepreneurship in business history", participa dessa discussão questionando o que ele chama de "a virada organizacional" nos estudos do empreendedorismo. O autor registra como as pesquisas na área do empreendedorismo estiveram, notadamente entre os anos I940 e I960, centradas sobre os fatores ambientais, contextuais e organizacionais, em detrimento do foco na figura do empreendedor, o que só voltou a ocorrer, segundo Cuff (2002), a partir da década de i970. Apenas esse debate, sobre o papel do indivíduo no processo empreendedor, já seria fator motivador suficiente para esta pesquisa. Contudo, no âmbito das discussões sobre o empreendedorismo, existem outros temas, igualmente ou ainda mais instigantes, que estimulam a pesquisar nesse campo, especialmente a questão da liderança como elemento do perfil comportamental do empreendedor e a sua relação com o processo de mudança organizacional, característico da etapa de consolidação e crescimento de novos negócios. Isoladamente, os temas liderança e mudança organizacional estão entre os mais pesquisados no campo da Adminis- 
tração (MCLEAN, 2005; HILL, I999; MANZ, I986, FAY; LÜHRMANN, 2004; GOODMAN; ROUSSEAU, 2004; HANNAN; PÓLOS; CARROLL, 2003). Possivelmente por conta disso, os estudos relacionando os dois temas são igualmente abundantes e têm sido capazes de produzir significativa evolução do conhecimento científico na área (BURKE; CHURCH, I992; SCHRUIJER; VANSINA, I999; NADLER; TUSHMAN, I990; NECK, I996; MANZ; BASTIEN; HOSTAGER, I99I). O comportamento empreendedor, por sua vez, tem recebido expressiva atenção por parte dos pesquisadores, sem, contudo, alcançar o nível de desenvolvimento dos temas citados anteriormente. Prova disso é o fato de que as pesquisas sobre comportamento empreendedor e liderança são bem mais escassas e, em sua maioria, remetem à questão fundamental do empreendedor visto pela ótica dos atributos de personalidade versus uma abordagem comportamental (DALGLISH; EVANS, 2000). A lacuna que se observa nessa área do conhecimento é a de um trabalho que busque relacionar, simultaneamente, tais variáveis. Assim, o objetivo desta pesquisa é identificar os comportamentos de liderança que o empreendedor utiliza para estimular as mudanças organizacionais que visam promover a consolidação e o crescimento de empresa emergente. O trabalho está delimitado pelo tipo de transição, dentro do ciclo evolutivo das empresas, que o negócio dos empreendedores experimentou. Isso significa que a pesquisa ficou concentrada numa determinada fase do ciclo evolutivo das organizações, que pode ser qualificado como aquele em que se dá a passagem do estágio inicial do negócio, ou sua infância, para a etapa de consolidação e crescimento que tende a culminar com a maturidade da empresa. Independentemente de os negócios terem ou não atingido a maturidade, a pesquisa focou o comportamento de liderança utilizado pelo empreendedor para promover as mudanças organizacionais necessárias para levar a empresa do estágio de startup à fase seguinte de desenvolvimento.

\section{REFERENCIAL TEÓRICO}

Diversos pesquisadores têm feito tentativas para estruturar e organizar a literatura sobre empreendedorismo produzida até os dias atuais. Entre os trabalhos, destacam-se os de Cunningham e Lischeron (I99I), Filion (I997), Low e MacMillan (I988) e Stevenson e Jarillo (I990). Embora apresentem variações em termos de abordagem e critério, qualquer dessas propostas de estrutura permite que se tenha uma visão ampla e abrangente do atual estágio das pesquisas em empreendedorismo.

Filion (1997) propõe que os pesquisadores na área sejam classificados em dois grandes grupos: os economistas e os comportamentalistas. O autor chama 
de economistas os que se interessaram, e ainda se interessam, em entender a importância do empreendedor como força motriz do sistema econômico. Eles são representados, inicialmente por Cantillon, Say e Schumpeter, e, posteriormente, por inúmeros outros pesquisadores que qualificaram o empreendedor como: a) um identificador de oportunidades de negócio, b) criador de negócios, c) tomador de riscos ou d) aquele que informa o mercado sobre novos elementos.

Outro acréscimo importante trazido pelos economistas, segundo Filion (I997), é a visão do empreendedor como agente econômico com um nível superior de tolerância ao risco o que permite-lhe operar em ambiente de ambiguidade e incerteza e ser recompensado pelo risco inerente às atividades que desenvolve. $\mathrm{O}$ autor sumariza a vertente econômica do pensamento sobre empreendedorismo com a apresentação de duas categorias de empreendedor: a) o organizador de negócios, que remete ao empreendedor de Cantillon e Say; b) o inovador, identificado com o empreendedor de Schumpeter. Para Filion (I997), a resistência natural dos economistas em aceitar modelos qualitativos, não quantificáveis, seria, na verdade, a grande motivação dos pesquisadores que formam a segunda categoria, os comportamentalistas. Filion (I997, p. 7) aponta David McClelland como o autor que efetivamente lançou as bases para a vertente comportamentalista das pesquisas em empreendedorismo, embora aponte que uma análise criteriosa do trabalho de McClelland, em especial The achieving society, do início dos anos I960, não revela conexões diretas entre "a necessidade de conquista e a decisão de se criar, possuir ou mesmo gerenciar um negócio". Isso significa que, mesmo sem estudar direta e especificamente o empreendedor ou o empreendedorismo, McClelland acredita que impulsos psicológicos dirigidos para a conquista e a realização devem ser vistos como antecedentes do desenvolvimento econômico. Esse ponto teria contribuído decisivamente para a abertura de uma nova via para o desenvolvimento das pesquisas científicas na área. O interesse primário dos comportamentalistas seria definir o empreendedor e suas características, o que foi tentado em inúmeros trabalhos de pesquisa que acabaram por gerar uma lista de atributos dos empreendedores. Se o trabalho de Filion (I997) consegue agrupar os estudos em empreendedorismo em apenas duas grandes categorias, Cunningham e Lischeron (I99I) propõem uma visão mais segmentada, representada por seis perspectivas básicas, ou escolas: escola dos "grandes personagens", das características psicológicas, clássica, da gestão, da liderança e do intraempreendedorismo. Apresentadas essas diversas linhas de pensamento sobre o empreendedorismo, está pavimentado o caminho para a discussão de uma das questões centrais desta pesquisa: como se comporta o empreendedor, em especial, como líder? A controvérsia sobre quem é o empreendedor, como ele se forma e de 
que maneira pode ser identificado e diferenciado é intensa no meio acadêmico, e os resultados pouco conclusivos e às vezes conflitantes das pesquisas indicam que o debate está longe de acabar. Importa aqui explicitar a adoção de uma abordagem comportamentalista para o desenvolvimento desta pesquisa, nos moldes proposto por Gartner (I988). Dessa forma, assume-se que o empreendedor não é alguém que é de determinada maneira, mas sim alguém que se comporta de determinada maneira.

\section{A LiderançA COMO ELEMENTO do COMPORTAMENTO EMPREENDEDOR}

Quando o tema é empreendedorismo, é comum encontrar referências, em geral repetidas e enfáticas, ao papel da liderança no processo de criação e desenvolvimento de novos negócios. Todavia, em se tratando de duas áreas nas quais as atividades de pesquisa não têm o consenso e o alinhamento de ideias como tônica, não era de esperar que essa relação se estabelecesse sem controvérsias e diálogos intelectuais intensos. Em um trabalho patrocinado pelo The Council for Excellence in Management and Leadership (RU), Perren (2000, p. I) declara o objetivo de "ajudar [...] a acompanhar a confusão semântica causada pelas similaridades e diferenças entre os termos empreendedorismo e liderança”. Um enfoque similar aparece no seguinte trecho: "Os grandes nomes da liderança nos negócios, Matsushita, Roddick, Branson, também são considerados grandes empreendedores. Isso significa que empreendedorismo e liderança são sinônimos?" (DALGLISH; EVANS, 2000, p. I).

Entender os diferentes papéis desempenhados por líderes e empreendedores, além dos gerentes, é também a proposta de Czarniawska-Joerges e Wolff (I99I) num estudo orientado por uma interpretação simbólica do contexto organizacional. Perren (2000, p. I), por sua vez, começa afirmando que "parece claro que empreendedores e líderes são diferentes". Ele parte de definições de dicionário para qualificar empreendedor como o empresário que toma a iniciativa e corre risco para ganhar dinheiro e líder como alguém que comanda, guia e inspira outros. A diferença está caracterizada, igualmente, pelo fato de que líderes atuam em diversas áreas da atividade humana - as forças armadas, as instituições religiosas, política e esporte, por exemplo -, enquanto a atuação dos empreendedores tende a ser relacionada, prioritariamente, com a criação e a operação de uma organização, seja ela uma empresa, um organismo público ou uma organização não governamental. Dalglish e Evans $(2000$, p. 3) examinaram a literatura relacionada à liderança e ao empreendedorismo, e concordam que as tarefas identi- 
ficadas com os papéis de líder e empreendedor são bastante diferentes, e identificaram a sugestão de que o empreendedorismo "não é percebido como parte necessária da liderança bem-sucedida [...] mas que liderança e/ou gestão é um elemento do sucesso empreendedor". Buscando uma saída para esse labirinto de definições, Perren (2000) elaborou análise comparativa baseada nos componentes conceituais (conceptual building blocks) de cada um dos construtos e considerou a importância atribuída pelas pesquisas aos fatores contextuais - variáveis sociais e econômicas - relacionados às atividades empreendedora e de liderança. Essa análise comparativa mostra que liderança e empreendedorismo compartilham três componentes conceituais: força pessoal, inovação/ visão e aceitação de risco. Os componentes conceituais mais característicos do empreendedorismo são: crença no controle sobre os eventos, tolerância à ambiguidade, necessidade de independência e identificação de oportunidades de mercado. A liderança, por sua vez, está mais associada com a comunicação e habilidades sociais, confiabilidade, habilidade para motivar, honestidade e integridade, confiança inspiradora, inteligência e habilidade cognitiva, conhecimento do negócio, real interesse nos outros e orientação para equipe.

Essa análise sugere que os termos empreendedorismo e liderança apresentam certa similaridade conceitual com uma considerável área de sobreposição, mas que, ainda assim, são claramente diferentes. Enquanto a liderança está mais diretamente associada aos componentes conceituais relacionados a pessoas, o empreendedorismo tende a estar mais ligado aos conceitos de busca por independência por meio da exploração de oportunidades de mercado (Perren, 2000).

\section{COMPORTAMENTO DE LIDERANÇA}

Buscando integrar as pesquisas realizadas nos últimos 50 anos na área do comportamento de liderança, Yukl, Gordon e Taber (2002) propõem uma taxonomia hierárquica que combina categorias, oferecendo uma proposta de estrutura para os comportamentos de liderança.

\subsection{COMPORTAMENTOS ORIENTADOS PARA A TAREFA}

a) Planeja atividades de curto prazo: atividade cognitiva, contínua, com aspectos que podem ser mais facilmente observados. Escrever planos, preparar orçamentos, reunir-se com pessoas para determinar como realizar uma tarefa são exemplos de como um líder planeja atividades de curto prazo. 
b) Explicita os objetivos das tarefas e as expectativas sobre cada papel: refere-se a dar diretrizes, guiar e coordenar as atividades, e garantir que as pessoas saibam o que e como fazer.

c) Monitora a operação e a performance: diz respeito a reunir informações sobre uma determinada operação, a performance individual dos subordinados, a qualidade do produto ou serviço gerado, e sobre o sucesso de determinado plano ou projeto.

\subsection{COMPORTAMENTOS ORIENTADOS PARA O} RELACIONAMENTO

a) Oferece suporte e encorajamento: refere-se a mostrar consideração, aceitação e preocupação com as necessidades e os sentimentos dos outros.

b) Reconhece realizações e contribuições: envolve dar mérito e demonstrar apreciação pelos outros em razão de performance efetiva, conquistas expressivas e contribuições importantes para a organização, de forma relativamente independente dos sistemas formais de recompensa da organização.

c) Desenvolve habilidades e a confiança dos liderados: o elemento crítico aqui é o coaching: comportamentos como mostrar a alguém uma forma melhor de realizar uma tarefa, a aprender com um erro e resolver um problema complexo, em vez de simplesmente oferecer a solução.

d) Consulta os liderados quando toma decisões: refere-se a envolver os subordinados na tomada de decisões importantes.

e) Dá aos liderados empowerment para que tomem a iniciativa na solução de problemas: inclui delegar e dar mais autonomia e poder de decisão aos subordinados.

\subsection{COMPORTAMENTOS ORIENTADOS PARA A MUDANÇA}

a) Monitora o ambiente externo: diz respeito a "varrer" e mapear o ambiente, por meio de análise de informações e tendências, consultas internas e externas.

b) Propõe estratégias inovadoras ou novas visões: refere-se à ideia de que uma visão influencia de maneira mais eficaz o comprometimento de um subordinado em relação a uma estratégia ou uma mudança.

c) Encoraja o pensamento inovador: trata de desafiar as pessoas a questionar suas premissas sobre o trabalho e considerar novas formas de realizá-lo mais eficientemente.

d) Corre risco para promover as mudanças necessárias: está associado à ideia de que promover grandes mudanças é sempre um processo arriscado. 


\subsection{AUTOIMAGEM DO LÍDER}

Com o intuito de complementar a taxonomia proposta por Yukl, Gordon e Taber (2002), escolhida como parâmetro de análise desta pesquisa, integrou-se o conceito de autoimagem do líder, proposto por Kets de Vries (I997). Segundo o autor, dependendo do tipo de experiência tida na infância, o indivíduo, quando adulto, tenderia a lidar com o mundo real de duas maneiras: por meio do narcisismo reativo, ou seja, experiências infantis negativas, caracterizadas por privações emocionais importantes que geram a busca por uma revanche contra o mundo (indivíduos que exibem, de forma explosiva, um senso de autoestima deturpado e se preocupam com emoções como inveja e vingança e com a conquista de vitórias humilhantes sobre os outros) ou pelo construtivismo (indivíduos equilibrados, com senso de autoconsideração e autoestima positivos).

\section{PROCEDIMENTO METOdOLÓGICO}

O objetivo desta pesquisa foi identificar que comportamentos de liderança o empreendedor utiliza para promover as mudanças organizacionais que visam à consolidação e ao crescimento de sua empresa. Denzin e Lincoln (2000) afirmam que a pesquisa qualitativa está interessada em estudar as coisas em seu ambiente natural, procurando dar sentido aos fenômenos ou interpretá-los de acordo com o significado que as pessoas lhes atribuem. O caráter exploratório do presente trabalho, ressaltado pela opção por uma abordagem qualitativa, aponta para a história de vida como um recurso metodológico apropriado, o que é reforçado com a proposição de Mills (I970 apud MANN, I992). Esta pontua que nenhum estudo na área das ciências sociais terá atingido seus objetivos intelectuais caso não tenha considerado as questões biográficas e históricas e suas intersecções no âmbito social. Queiroz (I99I, p. 6), que adota a denominação história de vida, afirma que sua definição envolve um narrador que relata sua existência ao longo do tempo com o objetivo de reconstituir sua trajetória e transmitir, ao pesquisador, sua perspectiva sobre as experiências que vivenciou. O pesquisador, por sua vez, busca, por meio desse relato, captar algo que extrapole o nível individual e possa fornecer indicações relativas ao contexto social do narrador, incluindo sua relação com seu grupo social mais próximo, sua profissão, sua classe social e a sociedade como um todo.

Participaram desta pesquisa três empreendedores selecionados com base nos seguintes critérios: estar à frente de negócios com crescimento expressivo nos últimos três anos e ter históricos de relacionamento diferentes com seus 
respectivos negócios, ou seja, empreendedores que aplicaram, de formas distintas, sua formação acadêmica e profissional ao negócio.

Optou-se pela entrevista em profundidade como técnica para construir as histórias de vida dos empreendedores que compõem o grupo de participantes desta pesquisa. As entrevistas em profundidade, do tipo semiestruturado, foram orientadas por um roteiro temático flexível. Tiveram seu áudio gravado e o material gerado, posteriormente, transcrito. Foram realizados oito encontros, que geraram cerca de I2 horas de entrevistas com os três empreendedores. Tendo em vista os objetivos da pesquisa, decidiu-se utilizar, no tratamento dos dados, a codificação temática, segundo a proposição de Flick (2004), baseada numa lista preliminar de categorias, conforme apontado por Basit (2003). Como parte do processo de análise dos dados, definiu-se um esquema de classificação que, segundo Basit (2003), teve origem no referencial teórico desenvolvido e nas questões de pesquisa que orientaram o estudo.

\section{PERFIL DOS ENTREVISTADOS E DAS EMPRESAS}

De acordo com os critérios estabelecidos, foram selecionados, para a pesquisa, três empreendedores cujos perfis e de suas respectivas empresas são apresentados no Quadro I.

QUADRO I

PERFIL GERAL DOS ENTREVISTADOS E DAS EMPRESAS*

\begin{tabular}{cccc}
\hline GÊNERO & MASCULINO & MASCULINO & MASCULINO \\
\hline Idade & 40 & 51 & 32 \\
\hline Local de nascimento & São Paulo & São Paulo & São Paulo \\
\hline Formação superior & Odontologia & Medicina/Patologia & Engenharia Metalúrgica \\
\hline Estado civil & Casado & Casado & Solteiro \\
\hline Filhos & 3 & 3 & 0 \\
\hline Sócios no negócio & Não & Sim & Sim \\
\hline Empresa & Dentalcorp & Diagnóstika & 1984 \\
\hline Ano/fundação & 1989 & 1985 & \\
\hline
\end{tabular}




\section{QUADRO I (CONTINUAÇÃO)}

\section{PERFIL GERAL DOS ENTREVISTADOS E DAS EMPRESAS*}

\begin{tabular}{cccc}
\hline GÊNERO & MASCULINO & MASCULINO & MASCULINO \\
\hline Atividade & Serviços & ServiçOs & Indústria \\
\hline Área & Saúde & Saúde & Metalurgia \\
\hline \multirow{2}{*}{ Ramo de atuação } & $\begin{array}{c}\text { Assistência } \\
\text { odontologia } \\
\text { Empresarial }\end{array}$ & $\begin{array}{c}\text { Laboratório de } \\
\text { patologia cirúrgica e } \\
\text { citológica }\end{array}$ & $\begin{array}{c}\text { Metais e ligas metálicas } \\
\text { não ferrosas, alumínio }\end{array}$ \\
\hline $\begin{array}{c}\text { Noffuncionários } \\
\text { Indicador de }\end{array}$ & 200 & 100 & 83 \\
Faturamento & $2003: 63 \%$ & $2003: 18 \%$ & $2003: 74 \%$ \\
\hline
\end{tabular}

*As empresas autorizaram por escrito a divulgação de seus nomes.

Fonte: Elaborado pelos autores com base em informações dos entrevistados.

\section{RESULTAdOS E ANÁLISES}

Com base na transcrição das entrevistas, procedeu-se, então, à análise detalhada de cada categoria e de sua consolidação nos quatro temas propostos: liderança orientada para a tarefa, para o relacionamento, para a mudança e a autoimagem do líder. A pesquisa qualitativa sinaliza que todas as respostas têm significados relevantes e que contribuem para a compreensão dos fenômenos pesquisados sob as perspectivas dos entrevistados (GODOY, I995). Com o intuito de olhar para os resultados e interpretá-los à luz dos temas e das categorias, extraindo o que há de mais profundo nos sentimentos e nas falas dos entrevistados, serão utilizados os seguintes recursos: as citações literais dos entrevistados são apresentadas destacadas do texto principal com recuo; os trechos dos relatos usados para ilustrar a análise aparecem, no texto principal, em itálico; e os aspectos mais diretamente associados ao item analisado são destacados em negrito.

\section{Tema: Liderança orientada para a tarefa}

As categorias de comportamento que compõem esse tema são: I) planeja atividades de curto prazo, 2) explicita os objetivos das tarefas e as expectativas sobre cada um, e 3) monitora a operação e a performance. 


\section{Categoria: Planeja atividades de curto prazo}

No relato do entrevistado 3, vários episódios exemplificam o comportamento de planejar para o curto prazo, como o processo de implantação da norma ISO 9000; o programa de mentoring para um novo colaborador:

[...] Olha, eu quero que você venha aqui uma vez por semana e fique no mínimo 3 horas com essa pessoa aqui dando mentoring pra ele, vai ser uma espécie de guru.

À medida que ele conduz as reuniões de focus group, nas quais afirma que se avalia o cumprimento de metas, por meio de uma série de métricas desenvolvidas especialmente para esse controle, discutem-se os motivos de eventuais divergências entre planos e resultados, e são reavaliados e redefinidos planos de ação. O Entrevistado I, por seu turno, relata alguns episódios nos quais esse tipo de comportamento aparece, por exemplo, na ocasião em que planejou a saída de sua mãe, que trabalhava na empresa dele. Uma vez decidido o desligamento, ele, então, marcou uma data para a saída dela, montou um plano de ação para transferência das atividades sob responsabilidade dela, definiu e envolveu os responsáveis pela execução do plano. Não existe no relato do entrevistado 2 nenhuma menção a esse tipo de comportamento. Ao contrário, encontram-se afirmações que mostram que planejar para o curto prazo não é prática usual:

[...] por um perfil muito conceitual meu, eu sou o camarada das ideias, eu sou o camarada de iniciar as coisas, mas eu sou indisciplinado na aplicação da metodologia; meu sócio, ao contrário, é a pessoa da implantação de tarefas novas.

Os comportamentos mencionados pelos entrevistados 2 e 3 estão alinhados com a definição de Yukl, Gordon e Taber (2002), segundo a qual, planejar significa decidir o que, como, por quem e quando será feito. De maneira menos direta que esses autores, mas corroborando essa perspectiva, Ulrich, Zenger e Smallwood (2000) afirmam que, entre os líderes, se observa o comportamento de demonstrar liderança formal capaz de integrar, prover recursos e coordenar as atividades de vários grupos de projeto.

Categoria: Explicita os objetivos das tarefas e as expectativas sobre cada um

O relato do entrevistado I permite identificar essa categoria de comportamento em algumas passagens, como a situação em que uma colaboradora interrompeu a entrevista para discutir com o entrevistado um investimento numa ação 
de responsabilidade social que havia sido proposta por uma ONG. Primeiramente, ele levantou informações sobre a proposta e questionou diversos aspectos. Em seguida, ponderou que o investimento só se justificaria se trouxesse resultados concretos, no caso, impacto direto na vida das pessoas que seriam auxiliadas. Indagou ainda se esse dinheiro não teria melhor uso se fosse aplicado de outra forma. No final, chamou para si a decisão, vetou o investimento, recomendou que aquela colaboradora, responsável pelo assunto, pesquisasse alternativas. No relato do entrevistado 3, pôde-se observar esse tipo de comportamento de maneira clara quando tratou um problema de desempenho, chamando a pessoa para uma conversa na qual explicou o que queria e quais eram os objetivos. Como nada aconteceu, ele, então, sentou junto com essa pessoa, elaborou um plano, definiu metas, explicou como as coisas deveriam ser feitas e estipulou um prazo.

O comportamento analisado aqui, e observado nos relatos dos entrevistados I e 3, está diretamente relacionado a explicitar responsabilidades. Para isso, o líder define objetivos específicos, que devem orientar o esforço para a realização de tarefas importantes, estimula a busca por maneiras eficientes para a condução do trabalho e fornece padrões e referências contra os quais os resultados podem ser avaliados, facilitando, assim, a avaliação do desempenho diante da tarefa (YUKL; GORDON; TABER, 2002). Três outros atributos de liderança - divulgar uma vasta gama de informações para os colaboradores, proporcionar os estímulos e recursos necessários à melhoria contínua e liderar com exemplos (ULRICH; ZENGER; SMALLWOOD, 2000) - podem ser associados à categoria em análise e ilustrados por comportamentos mencionados no relato do entrevistado I, quando relata viagens com os colaboradores para o Rio de Janeiro:

[...] na Dentalcorp, [...] a gente sai daqui às 5 da manhã, para estar umas 9 h3o no Rio trabalhando, então eu dou várias mensagens pra todos e faço questão de juntar gerentes de diferentes áreas, porque aí todo mundo fica sabendo. Primeiro, eu podia mandar os caras de carro e ir de avião, mas eu estou preocupado em conter custo. [...] E até brinco, quando a gente para umas $7 \mathrm{~h}[\ldots]$ eu falo [...] pensa o seguinte, a essa hora o pessoal [concorrente] ainda está dormindo cara, a gente está duas horas na frente deles.

Essa categoria de comportamento faz parte do perfil de liderança dos entrevistados i e 3 , enquanto o entrevistado 2 demonstra fazer pouco uso desse comportamento.

Categoria: Monitora a operação e a performance

O entrevistado 3 diz que se trata de um comportamento usual seu: 
[...] hoje eu estou aqui dentro, eu sou um diretor operacional, você entendeu? Então eu tenho que ficar ligando, cobrando, eu faço isso. Aí eu sou às vezes um pouco chato até, nesse sentido, eu cobro [...] eu sou muito exigente comigo mesmo, isso é um lance que eu tenho que trabalhar também um pouco, sabe, porque eu me cobro demais e também acabo cobrando as pessoas.

Da mesma forma, o relato do entrevistado I apresenta alguns exemplos de adoção desse tipo de comportamento, como a passagem em que ele narra estar perturbado por ter acabado de receber a informação de que as metas do trimestre anterior não tinham sido atingidas, ou quando afirma:

[...] no dia a dia eu sou um cara muito focado em resultado, então eu cobro muito.

O entrevistado 2, apesar de afirmar que não controla, demonstra que, eventualmente, se engaja em atividades que podem, sim, ser entendidas como monitoramento de atividades de desempenho e cita a avaliação $360^{\circ}$ :

[...] eu fico querendo saber como a coisa está andando, eu sou o cara que permeia cada cantinho, cada departamento da empresa como um todo, mas não de uma forma disciplinada, eu sou muito indisciplinado, eu não busco canais formais não.

Os comportamentos descritos aqui descrevem como o comportamento relativo a monitorar desempenho, conforme a descrição de Yukl, Gordon e Taber (2002), é promover o apoio entusiástico às metas do negócio. Tal prática, descrita por Ulrich, Zenger e Smallwood (2000), pode também ser associada aos comportamentos descritos pelos entrevistados.

Os relatos sugerem que os três entrevistados adotam comportamentos relacionados a monitoramento e controle. A diferença que se observa, no entanto, é que, enquanto os entrevistados i e 3 o fazem de maneira formal e encaram isso como algo natural, inerente à atividade gerencial, o entrevistado 3 se comporta dessa maneira esporádica e informalmente, além de demonstrar certa resistência à atividade de gerência.

Em síntese, os resultados obtidos pela análise das três categorias que compõem o tema liderança orientada para a tarefa, com base nos comportamentos que os entrevistados exibem, mostram que não existe convergência entre os entrevis- 
tados quando se trata dos comportamentos de liderança relacionados com tarefa. O entrevistado 3 demonstra considerável facilidade para transitar entre as três categorias de comportamento relacionadas ao tema, já o entrevistado I demonstra utilizar os comportamentos relacionados à tarefa de forma diferenciada, com ênfase maior em explicitar objetivos e expectativas, e o entrevistado 2, por sua vez, se mostrou muito pouco confortável com os comportamentos relacionados com a liderança orientada para a tarefa.

O Quadro 2 resume os resultados obtidos por meio da análise das três categorias que compõem o tema liderança orientada para tarefa, com base nos comportamentos que os entrevistados exibem.

\section{QUADRO 2}

RESUMO DOS COMPORTAMENTOS ORIENTADOS PARA TAREFA EXIBIDOS PELOS ENTREVISTADOS

\begin{tabular}{cccc}
\hline COMPORTAMENTO & ENTREVISTADO 1 & ENTREVISTADO 2 & ENTREVISTADO 3 \\
\hline Planeja atividades de curto prazo & NÃO EXIBE & NÃO EXIBE & EXIBE \\
\hline $\begin{array}{c}\text { Explicita os objetivos das tarefas e as } \\
\text { expectativas sobre cada um }\end{array}$ & EXIBE & NÃO EXIBE & EXIBE \\
\hline $\begin{array}{c}\text { Monitora a operação e a performance } \\
\text { EXIBE }\end{array}$ & NÃO EXIBE & EXIBE \\
\hline
\end{tabular}

Fonte: Elaborado pelos autores com base em informações dos entrevistados.

\section{Tema: Liderança orientada para o relacionamento}

A taxonomia proposta por Yukl, Gordon e Taber (2002) sugere que os seguintes comportamentos estejam associados a esse tema: I) oferece suporte e encoraja, 2) reconhece realizações e contribuições, 3) desenvolve habilidades e confiança, 4) consulta para decidir e 5) dá empowerment para solução de problemas.

\section{Categoria: Oferece suporte e encoraja}

No relato do entrevistado I, é possível encontrar diversas passagens que demonstram como ele valoriza as pessoas e se preocupa com seus colaboradores: é importante exercer o papel de "grande motivador", papel que, aliás, ele acha que nunca vai deixar de desempenhar. 
[é importante] mostrar para as pessoas aqui dentro que a gente tem muito para crescer e muito para conquistar [...] eu tenho percebido uma coisa, as pessoas mais bem-sucedidas que eu vejo, elas têm uma habilidade que é se relacionar bem. Isso eu acho que é uma grande habilidade, e essa eu tenho [...]

No relato do entrevistado 2, notam-se passagens que denotam suporte, consideração e preocupação com os colaboradores. Os seguintes trechos são ilustrativos disso:

[...] eu puxo não só a visão da empresa, como a visão da carreira delas, sabe, então eles sentem que eu procuro demonstrar para eles que caminhos podem seguir na carreira deles que eles até então não haviam enxergado [...] se alguém me interromper e disser "Olha, eu estou com uma dúvida aqui", então eu paro de ver o meu caso e passo a ver o dele. Isso, eu sei, dá um baita cansaço, eu não consigo terminar a minha coisa pra [...] é um defeito isso, mas eu atendo a pessoa.

O relato do entrevistado 3 apresenta diversas situações, por exemplo, por ter identificado os problemas causados por um certo afastamento seu das atividades da nova unidade da empresa, hoje, ele praticamente "mora lá", sua presença na fábrica é muito frequente, seu envolvimento com as pessoas é muito intenso e ele participa muito mais do dia a dia da planta, inclusive no "chão de fábrica". A reação dele a um acidente na linha de produção também ilustra o comportamento de suporte:

[...] a primeira coisa que eu fiz foi estar mais próximo dessas pessoas, conversando, dialogando e dando segurança pra elas [...] o pessoal hoje está pilhado, porque a fábrica agora voltou e ninguém foi mandado embora, porque eu, simplesmente, eu transmiti essa segurança naquele momento.

Esses comportamentos exibidos mostram "consideração, aceitação e preocupação pelas necessidades e pelos sentimentos das pessoas", e devem ser vistos como um "aspecto típico e significativo do comportamento de liderança", a expressão do conceito de suporte proposto por Yukl, Gordon e Taber (2002, p. 20). Em linha com o conceito de suporte proposto por Yukl, Gordon e Taber (2002), Kouzes e Posner (apud HESSELBEIN; GOLDSMITH; BECKHARD, 200I) ensinam que criar uma comunidade de valores compartilhados é função do líder. 


\section{Categoria: Reconhece realizações e contribuições}

Nenhum dos relatos é muito enfático em relação a essa modalidade de comportamento. No relato do entrevistado 3, é possível identificar algumas ações referentes à implantação de um programa de premiações por ideias mais interessantes:

[os funcionários] vocês estão mais qualificados [...] e a gente tenta valorizar, mostrando, olha [...] conseguimos melhorar o resultado.

O entrevistado I menciona o episódio de desligamento de sua mãe da empresa, ocasião em que realizou uma cerimônia de homenagem a ela, e a implantação de um programa de participação em resultados (bônus). O entrevistado 2 relata a implementação de um programa de participação societária para a equipe médica, que ele justificou afirmando que:

[...] a gente entende que profissionais liberais diferenciados, como são os médicos, todos são muito bem formados, eles precisam ter o estímulo de um dia serem donos de uma empresa.

Além disso, afirma que não é muito de festejar, que "suas comemorações são bem poucas" e que isso se explica pelo fato de ele achar que a conquista de metas é algo natural, que faz parte do processo.

Os comportamentos descritos aqui estão relacionados com dar mérito e demonstrar apreciação pelos outros em razão do desempenho, conquista expressiva e contribuições importantes, o que, de acordo com Yukl, Gordon e Taber (2002), caracteriza o comportamento de reconhecer realizações e contribuições. Embora afirmem que, geralmente, o reconhecimento é dado com recompensas tangíveis, esses autores defendem a ideia de que esse tipo se caracteriza por ser mais pessoal e independente dos sistemas formais de recompensa da organização.

\section{Categoria: Desenvolve habilidades e confiança}

Duas citações do entrevistado I ilustram essas ações: a primeira surge quando comenta sobre a importância da capacitação dos colaboradores em momento de mudança que a empresa enfrenta. Ele afirma que vem daí a atenção especial em desenvolver as pessoas e reforçar a equipe, comprar e ler livros que tragam mensagens que possam ser compartilhadas com os colaboradores. 
[...] me recomendaram ler o Good to Great no original, mas eu comprei a versão em português porque, na verdade, acho que é um negócio que eu quero disseminar para o meu pessoal, e em português fica mais fácil.

No relato do entrevistado 2 , ele destaca que o momento de mudança que a empresa atravessa tem gerado nele uma sensação ligada a prazer, pois ele passa a ensinar os mais jovens, criando uma metodologia para disseminar sua forma de trabathar, que era, na verdade, a forma de trabalhar do laboratório. Em outro momento, afirma que o importante é:

$[\ldots]$ tocar a rotina, [...] mas ao mesmo tempo, eles precisam continuar se desenvolvendo como médico, criar uma visibilidade no mercado, se tornar uma referência na área e ter prazer nisso.

O entrevistado 3, falando do processo de mudança e criação de uma cultura organizacional, aponta algumas ações, mais de caráter institucional, que refletem a preocupação com desenvolvimento dos colaboradores:

[...] nós investimos muito em treinamento, em conversa, em comunicação.

Lembra ainda que gosta de tentar mudar as pessoas, de "trabalhar" as pessoas, explicar, orientar, dar oportunidade para que elas façam treinamento e se desenvolvam, costuma utilizar processos informais de comunicação e se envolver mais profundamente.

Esses comportamentos se enquadram no conceito de desenvolver habilidades e confiança proposto por Yukl, Gordon e Taber (2002), caracterizado pelo coaching, em como fazer e estimular o aprendizado pelo questionamento, pelo erro e desafio.

\section{Categoria: Consulta para decidir}

Não existe, em nenhum dos três relatos, menção explícita ao comportamento de consultar para decidir, entendido aqui como a promoção do envolvimento dos colaboradores no processo de tomada de decisões importantes (YUKL; GORDON, TABER, 2002). A ausência de menções explícitas à consulta para decidir poderia estar relacionada a dois aspectos apontados pela literatura como característicos do perfil comportamental dos empreendedores. O primeiro é mencionado por Schein (I992), que afirma que o empreendedor, como criador e construtor da cultura organizacional de sua empresa, é o agente que inicia esse 
processo de geração de cultura, por ser um indivíduo que tem premissas fortes sobre como as coisas devem ser. O outro aspecto refere-se a uma característica de personalidade, atribuída aos empreendedores pelos defensores da abordagem dos traços, o locus de controle interno, a necessidade que o empreendedor teria de se manter no controle de tudo que cerca o seu negócio.

\section{Categoria: Dá empowerment para solução de problemas}

O entrevistado I apresenta várias situações e, em uma passagem, afirma que considera crítico na etapa de crescimento, delegar mais para poder se dedicar a funções mais estratégicas. Para isso, tem procurado, ainda sem sucesso, encontrar um profissional para assumir a função de superintendente-geral. Sobre sua equipe e o desafio de crescer, afirma:

[...] eu não posso crescer mais se eu não tiver uma boa equipe [...] que assuma riscos, que tome decisões, que tenha foco em resultados [...] Vamos investir nas pessoas que estão aqui e vamos dar empowerment para essas pessoas tomarem decisões e ajudarem a empresa a crescer.

Para o entrevistado 2, pode-se dizer que alguns trechos de seu relato apenas sugerem uma visão positiva do empowerment, sem, contudo, caracterizar esse comportamento como uma prática do entrevistado. Os seguintes trechos ilustram essa situação:

[os médicos] precisam ter o estímulo de um dia serem donos de uma empresa [...] é absolutamente contraindicado você achar que vai ficar na minha sombra.

Já o relato do entrevistado 3 não explicita nenhum comportamento relacionado a dar empowerment.

Esses episódios estão alinhados com a proposta teórica de Yukl, Gordon e Taber (2002) para a postura de dar empowerment para solução de problemas e, esse comportamento relaciona-se a delegar, dar autonomia e poder de decisão aos colaboradores. Esses comportamentos também podem ser relacionados a perspectivas de outros autores sobre o tema, como a ideia de que líderes se comportam para desenvolver equipes autogerenciáveis (ULRICH; ZENGER; SMALLWOOD, 2000); um dos passos para a concretização de uma mudança organizacional é oferecer empowerment (KOTTER; COHEN, 2002).

Considerando o conjunto das categorias que compõem o tema liderança orientada para o relacionamento, o Quadro 3 resume o perfil dos entrevistados de acordo com os comportamentos que eles exibem. 
QUADRO 3

RESUMO DOS COMPORTAMENTOS ORIENTADOS PARA O

RELACIONAMENTO EXIBIDOS PELOS ENTREVISTADOS

\begin{tabular}{cccc}
\hline COMPORTAMENTO & ENTREVISTADO 1 & ENTREVISTADO 2 & ENTREVISTADO 3 \\
\hline Oferece suporte e encoraja & EXIBE & EXIBE & EXIBE \\
\hline Reconhece realizações e contribuições & $\begin{array}{c}\text { EXIBE } \\
\text { (discretamente) }\end{array}$ & NÃO EXIBE & EXIBE \\
\hline Desenvolve habilidades e confiança & $\begin{array}{c}\text { EXIBE } \\
\text { (instrumentos } \\
\text { institucionais) }\end{array}$ & EXIBE & EXIBE \\
\hline $\begin{array}{c}\text { Consulta para decidir } \\
\text { NãO EXIBE }\end{array}$ & NÃO EXIBE & NÃO EXIBE \\
\hline $\begin{array}{c}\text { Nempowerment para solução de } \\
\text { problemas }\end{array}$ & EXIBE & NÃO EXIBE & NÃO EXIBE \\
\hline
\end{tabular}

Fonte: Elaborado pelos autores com base em informações dos entrevistados.

Tema: Liderança orientada para a mudança

Segundo Yukl, Gordon e Taber (2002), os comportamentos associados a esse tema são: I) monitora o ambiente externo, 2) propõe estratégias inovadoras ou novas visões, 3) estimula o pensamento inovador e 4) assume riscos para promover as mudanças necessárias.

\section{Categoria: Monitora o ambiente externo}

Em três passagens do relato do entrevistado I, é possível identificar essa categoria: é membro do conselho do condomínio onde mora, exerce um cargo de diretoria no sindicato, participa de uma confraria e é membro ativo do Rotary Club. Segundo ele, em todas essas atividades existem potencial para geração de valor, de algum retorno para a empresa e, por isso, essas atividades devem ser sempre valorizadas. Seguindo a mesma linha de raciocínio, o entrevistado destaca o relacionamento com a Endeavor que, em sua visão, pode ser definida como uma organização capaz de "amplificar o sonho" do empreendedor, "transformar o sonho, que está meio esfumaçado, numa imagem mais nítida".

No relato do entrevistado 2, duas passagens são marcantes em relação à ocasião em que as divergências entre um sócio e o entrevistado se ampliaram porque este havia identificado uma tendência e antecipado uma mudança. $\mathrm{O}$ relato aponta que havia divergências sobre como lidar com um fator novo na época, e que, para o entrevistado, tinha vindo para mudar radicalmente as condições de mercado: os convênios médicos. Percebeu que havia uma certa instabilidade lá, cometiam-se erros 
grosseiros, e os médicos e usuários estavam insatisfeitos. A partir dessa percep̧ão, ele decide ir conversar com um diretor do hospital.

O entrevistado 3 conta que começou a viajar bastante para o exterior, visitando fábricas, feiras, conhecendo fornecedores e fazendo contatos comerciais. Ele diz que, além de prospectar o mercado e buscar parcerias, essas viagens tinham o objetivo de colher informações que pudessem ajudar no negócio interno, na operação nacional, $e$ completa afirmando que foi por meio disso que começou a desenvolver uma visão mais global do negócio.

Yukl, Gordon e Taber (2002) pontuam que se trata do processo de reunir, analisar e interpretar informações relativas a preocupações e demandas de clientes, além de estar alinhado à necessidade de sensibilidade ambiental para alterar o status quo, conceito citado por Conger e Kanungo (I987).

Categoria: Propõe estratégias inovadoras ou novas visões

O entrevistado I afirma que sua empresa está atravessando uma importante fase de crescimento, focada na consolidação dos negócios no Brasil e na expansão internacional, proposta estratégica que, por seu caráter inovador, foi base para a elaboração de um case-study por professores da Universidade de Harvard. Essa mesma proposta é reforçada com a seguinte citação:

[é importante] mostrar que a gente tem muito para crescer e conquistar, aqui e na América Latina.

Em outro trecho, aparece o Dentalpeople 2010, um símbolo criado (com os algarismos da data $\left.1^{0} .1 .2010\right)$ para representar a visão do entrevistado sobre of futuro da empresa e dos seus colaboradores.

O entrevistado 2 ilustra a prática do comportamento em análise:

Eu me sinto hoje muito como se eu fosse um cartola, assim, que vai buscar estrelas para o seu time $[\ldots]$ as primeiras entrevistas médicas passam por mim [...] eu falo: "Olha, eu preciso mostrar para você que esse é um ambiente legal para você vir".

O entrevistado 3 apresenta passagens relacionadas à articulação de visões:

[...] eu tenho informação de que essas pessoas que participam do focus group não têm e talvez eu tenha uma visão mais forte [...]. E aí eu discurso e falo: "Olha, nós temos uma coisa linda, maravilhosa". 
Esses comportamentos estão relacionados com articular uma visão inspiradora através de: I. uma associação com os valores e interesses dos colaboradores; 2. de uma comunicação entusiasmada e confiante; 3. da construção de uma percepção de viabilidade (YUKL; GORDON; TABER, 2002); e 4. de uma abordagem inspiradora e emocional, associada ao líder carismático (CONGER; KANUNGO, I987, p. 64I).

Categoria: Estimula o pensamento inovador

O entrevistado 3 diz que considera fundamental ter participado direta e ativamente em processos, como um facilitador, alguém que age no sentido de fazer que as pessoas se sintam mais livres para dar ideias, mais à vontade para opinar, e que sua prática de comunicar visões de forma emocional e apaixonada não é feita apenas nos focus group, que ela acontece também com o pessoal operacional, e que muitas vezes a resposta desses colaboradores é muito boa, trazendo ideias, propostas de melhoria.

Já nos relatos dos entrevistados i e 2, não se identificam práticas que possam ser claramente associadas ao comportamento em questão. Sugere-se que estão mais preocupados em desenvolver uma cultura organizacional própria, objetivo que, aparentemente, já teria sido alcançado pelo entrevistado 3, valorizando a transmissão de suas crenças pessoais, como sugere Schein (I992, p. 228), em vez de estimular intelectualmente os colaboradores, fato que poderia levar ao surgimento de ideais novos, eventualmente desassociados dos seus próprios.

Categoria: Assume riscos para promover as mudanças necessárias

O entrevistado I relata que, no início de sua vida profissional, resolveu aproveitar uma oportunidade para se tornar sócio de cinco colegas de turma, abrir um consultório e se estabelecer como dentista antes mesmo de terminar o curso de Odontologia. Mais adiante, na fase inicial do negócio, o empreendimento não crescia na velocidade desejada, e o entrevistado decidiu se arriscar para acelerar o desenvolvimento do negócio. Primeiro, desmontou um dos consultórios para montar um consultório-volante num trailer, depois, outro dos consultórios de São Paulo foi desmontado para possibilitar que o entrevistado se associasse a uma empresa de assistência médica para abrir um escritório regional no Rio de Janeiro. Em outra passagem, que conta que o próprio ciclo de crescimento, aliado à falta de estrutura e à determinação do entrevistado em não deixar passar oportunidades, foi responsável por uma grave crise financeira durante o ano de 1997, o que estimulou o crescimento do negócio. A própria opção pela expansão internacional, proposta estratégica que, por seu caráter inovador, foi base para a elaboração de um case-study por professores da Universidade de Harvard, reflete uma postura de correr risco para mudar. 
O entrevistado 2 lembra que, no período em que foi plantonista do prontosocorro num hospital na periferia de São Paulo, passou a ser "o cardiologista do hospital", se não de direito, ao menos de fato, pois os médicos formados que atendiam no hospital "eram péssimos", geralmente vinham de outros Estados brasileiros com uma formação profissional precária. Comenta ainda que, utilizando a sala de necrópsia da faculdade e uma estrutura simples montada em sua casa, começa a realizar seus primeiros exames, mais uma vez buscando antecipar sua carreira.

O entrevistado 3 acredita que empreender é "ir para o risco" e diz que na época (início de sua jornada empreendedora) pensava: "deixa eu errar". Nessa mesma época, seu pai decide se afastar da empresa, e, assim, antes de terminar a faculdade, o entrevistado, com o suporte da irmã, que cuidava da administração, do pessoal e das finanças, começa a encarar o desafio de desenvolver as pastilhas de pó metálico e com isso transformar a Mextra e compra uma nova máquina quando não havia ainda nem acabado de pagar o financiamento da primeira máquina.

Yukl, Gordon e Taber (2002) apontam que esses comportamentos são típicos de assumir riscos pessoais para vencer resistências, promover mudanças e alterar a realidade à sua volta. A ideia encontra eco na proposta de Conger e Kanungo (I987) para o perfil do líder carismático, que ressalta o comportamento de defender e apoiar, de forma desinteressada, os colaboradores, assumindo, assim, riscos e custos pessoais expressivos. Ulrich, Zenger e Smallwood (2000) afirmam que o líder experimenta, assume riscos e busca oportunidades por meio de confronto e questionamento do status quo.

O Quadro 4 apresenta um resumo do perfil comportamental dos entrevistados, no tocante a comportamentos de liderança relacionados à mudança.

QUADRO 4

RESUMO DOS COMPORTAMENTOS ORIENTADOS PARA MUDANCA EXIBIDOS PELOS ENTREVISTADOS

\begin{tabular}{cccc}
\hline COMPORTAMENTO & ENTREVISTADO 1 & ENTREVISTADO 2 & ENTREVISTADO 3 \\
\hline Monitora o ambiente externo & EXIBE & EXIBE & EXIBE \\
\hline $\begin{array}{c}\text { Propõe estratégias inovadoras ou } \\
\text { novas visões }\end{array}$ & EXIBE & EXIBE & EXIBE \\
\hline $\begin{array}{c}\text { Estimula o pensamento inovador } \\
\text { Assume riscos para promover as } \\
\text { mudanças }\end{array}$ & NÃO EXIBE & NÃO EXIBE & EXIBE \\
\hline
\end{tabular}

Fonte: Elaborado pelos autores com base em informações dos entrevistados. 
Tema: Autoimagem como líder

O entrevistado I foi bastante direto e afirmou que se vê como um bom líder. Ele não se acha autoritário, diz que, por conta de ser muito controlador e detalhista, cobra muito, repreende muito, mas não guarda rancor. Acredita que seus colaboradores não o veem como um líder autoritário, embora muitos se sintam pressionados pelo nível de cobrança.

Enfim, entende seu papel de líder como um facilitador, alguém que está lá próximo, ajudando as pessoas a se desenvolverem, e que essa função passa por mostrar quais são os pontos-chave para se alcançar of futuro desejado:

[meu papel como líder é] fazer que as pessoas vejam que a gente está indo num caminho adequado, que a gente está na estrada certa, isso é importante todo mundo saber.

O relato do entrevistado 2 apresenta passagens que mostram certa resistência em se perceber como líder. Ele se enxerga como alguém que tem vencido suas batalhas pelo trabalho, pela dedicação, pela perseverança:

[...] se a gente entender liderança como perseverança, aí tudo bem, aí talvez seja possível me enxergar como alguém que exerce liderança.

$\mathrm{Na}$ verdade, declara sua preferência por uma imagem de empreendedor em vez de líder:

[...] eu me vejo mais confortavelmente como empreendedor do que como líder, quer dizer, como empreendedor, eu acho que eu quis mudar uma situação.

O entrevistado 3 declara que, embora desenvolva sem problemas atividades mais relacionadas às rotinas e ao dia a dia operacional, e se envolva bastante com detalhes e tarefas, sente-se mais à vontade no papel do visionário.

Essa percepção se completa com a afirmação de que não se considera um facilitador totalmente formado ainda, embora diga que acha que tem melhorado nesse aspecto, mas que se vê como uma pessoa que sabe muito bem aonde quer chegar, consegue mostrar o caminho para as pessoas e fica "empurrando" para que as coisas aconteçam. Ele ainda resume a autoimagem como líder, afirmando que se vê como aquele cujo papel principal não é operacional, pelo contrário, diz que operacionalmente pretende ser alguém dispensável, mas sim pensar a Mextra para daqui a cinco ou dez anos. 
A autoimagem mescla autoconfiança e autoestima com a consciência da necessidade de evoluir e melhorar como líder, e encontra respaldo em características de líderes apresentadas por Ulrich, Zenger e Smallwood (2000), que descrevem o líder como alguém que crê em si mesmo, é autoconfiante, mas com humildade Handy (apud HESSELBEIN; GOLDSMITH; BECKHARD, 200I) corrobora essa perspectiva afirmando que somente a crença em si mesmo produz confiança para prosseguir rumo ao desconhecido e permite influenciar outros para irem aonde ninguém esteve antes.

Com base nesses resultados, observa-se que os três entrevistados têm autoimagens de líder diferentes. Os entrevistados I e 3 se veem como facilitadores que conseguem mobilizar e conduzir as pessoas aos objetivos desejados, embora reconheçam que podem e devem continuar evoluindo como líderes. O Entrevistado 2 não se enxerga como líder, aponta lacunas importantes em seu perfil comportamental e credita seu sucesso à sua postura empreendedora.

\section{CONCLUSÕES}

Este estudo se propôs a identificar comportamentos de liderança adotados por empreendedores para promover as mudanças organizacionais necessárias ao crescimento de seus negócios. Por meio da revisão de literatura apresentada, pôde-se avaliar a complexidade que caracteriza os temas envolvidos com esse objetivo, particularmente no tocante à relação entre liderança e empreendedorismo, ou, de forma mais específica, no que se refere ao papel da liderança como elemento do comportamento do empreendedor.

O arcabouço teórico sobre a caracterização psicológica e comportamental dos empreendedores, fonte primária e inesgotável de controvérsia acadêmica entre os pesquisadores do empreendedorismo, está representado nos resultados desta pesquisa. Os relatos analisados vão ao encontro da perspectiva integracionista do comportamento empreendedor, já que evidenciam que apenas uma visão holística dos entrevistados poderia explicar por que se tornaram empreendedores. Por um lado, as histórias de vida desses indivíduos estão repletas de menções a fatores relacionados à personalidade, amplamente mencionados na literatura correspondente, tais como: necessidade de conquista e realização, independência, autoconfiança e energia. Por outro, remetem aos aspectos relativos à abordagem demográfica, como a existência de referências (ídolos, exemplos), escolaridade, situação socioeconômica, experiência profissional e hábitos no trabalho.

Também em sintonia com as referências teóricas, as narrativas mencionam, ainda, fatores contextuais, como as questões econômicas geradas pelo nascimento de filhos e a constituição de família, no caso de dois dos empreendedores, e 
a existência de uma estrutura organizacional embrionária do empreendimento, para o outro.

Uma das questões suscitadas pela literatura que trata do binômio conceitual liderança-empreendedorismo se refere à eventual sobreposição das figuras do líder e do empreendedor. Em relação a tal aspecto, os resultados desta pesquisa, em especial os apresentados na categoria autoimagem como líder, sugerem que, assim como proposto por Perren (2000), líderes e empreendedores são figuras diferentes. Do ponto de vista empírico, os empreendedores entrevistados, ao longo de seus relatos, deixaram claro que se enxergam, prioritária e inequivocamente, como empreendedores e que o exercício da liderança é apenas um requisito para a atividade empreendedora.

Essa conclusão corrobora, pelo menos parcialmente, a perspectiva apresentada por Dalglish e Evans (2000) e também encontra suporte no senso comum, de que a liderança seria um elemento essencial para o sucesso do empreendedor, enquanto o empreendedorismo não seria percebido como necessário ao bom exercício da liderança. Estabelecida essa distinção, cabe agora discutir os empreendedores no contexto do exercício da liderança visando à mudança e ao crescimento. Todos eles definem o ambiente operacional de suas organizações como sendo marcado pela mudança orientada para o crescimento, algo que poderia, grosso modo, ser descrito como o estágio 2 do modelo de ciclo de vida de organizações de Steinmetz (1969). Todos descrevem um ambiente que deixou de ser um one-man-show e passou a exigir deles uma atuação efetiva como um diretor, um gerente-geral. Tiveram de combinar o papel gerencial com a imagem de empreendedor carismático, por conta do sucesso que obtiveram; escolheram seus "braços direitos", passaram a delegar mais, começaram a operar com mais níveis hierárquicos e criaram algum artifício para aperfeiçoar o produto ou serviço que estava associado ao início do negócio.

De acordo com o que propõe Steinmetz (1969), passaram a valorizar a gestão financeira e a adoção de boas práticas gerenciais, e procuraram aprender por meio de contatos com outros empresários, com organismos de apoio, como a Endeavor, ou de treinamento e educação formal. Como também é característico desse estágio, focam suas energias na expansão e no crescimento, já que os resultados gerados possibilitam o reinvestimento de algum capital, e sua disposição para o risco tende a aumentar ligeiramente.

Apesar da similaridade de percepção sobre o ambiente, nota-se que, do ponto de vista organizacional, as empresas encontram-se em estágios diferentes de desenvolvimento. Dois dos empreendedores indicam que suas empresas já têm uma cultura própria, que talvez não estejam ainda perfeitamente consolidadas, mas que já servem para caracterizar esses ambientes organizacionais. Poder-se-ia, então, afirmar que existe, nessas empresas, ao menos um embrião, 
relativamente fortalecido de cultura organizacional. Para um deles, a preocupação maior está em transmitir essa cultura para a nova unidade instalada em outra localidade, enquanto o outro trabalha para garantir a disseminação dessa cultura no momento de expansão que a empresa vem atravessando nos últimos anos.

O terceiro empreendedor, entretanto, descreve sua empresa como um ambiente que ainda carece de uma diretriz cultural mais bem definida, tanto que uma área voltada para esse fim foi implantada recentemente. A diferença talvez possa ser explicada pela ênfase dada pelos dois primeiros empreendedores para a adoção de alguns comportamentos de liderança: utilizam mais intensamente a prática de liderar pelo exemplo, explicitando, durante o exercício de suas atividades gerenciais, seus valores, suas maneiras de encaminhar soluções e suas expectativas, o que coincide com a formulação de Schein (I992) sobre os mecanismos primários de consolidação e transmissão de cultura organizacional utilizados pelo líder-empreendedor. Daí, é possível especular que a prioridade dada a esse tipo de comportamento por esses dois empreendedores talvez tenha sido responsável pela criação e consolidação mais rápidas de uma cultura organizacional em suas empresas. A referida especulação conduz à outra. Haveria uma relação entre a capacidade de, por meio do exemplo, fazer surgir uma cultura organizacional mais evidente e a autoimagem de líder do empreendedor?

As duas especulações, tomadas em conjunto, permitem considerar uma hipótese no sentido inverso ao do raciocínio apresentado pela literatura. Schein (I992) afirma que o líder-empreendedor é o agente que cria e transmite a cultura organizacional por meio, principalmente, de mecanismos de explicitação e exemplo. A hipótese inversa é de que um empreendedor que não é capaz de utilizar os mecanismos definidos por essa proposta teórica para consolidar uma cultura para a sua organização não conseguiria se enxergar como líder. Os resultados desta pesquisa parecem apontar nessa direção, quando mostram que aquele empreendedor que não lidera pelo exemplo, e cuja empresa não apresenta cultura organizacional consolidada, não se vê como líder, mas apenas como empreendedor; enquanto os demais, que exercitam os mecanismos primários definidos pela teoria e que afirmam que suas empresas já possuem alguma cultura organizacional, parecem confortáveis com a autoimagem de líder.

Com base nesse sumário de conclusões, acredita-se que os resultados apresentados possibilitaram um avanço na compreensão dessas proposições, sobretudo quando associado à identificação do perfil comportamental de liderança de empreendedores. Obviamente, tais resultados devem ser avaliados à luz das limitações inerentes à pesquisa. Deve-se levar em conta que as conclusões, aqui apresentadas têm sua validade circunscrita às condições nas quais o estudo foi realizado, ou seja, o confronto da literatura existente com a narrativa de três empreendedores, por meio de relatos livres, de suas histórias de vida, de suas 
impressões sobre suas empresas, o contexto ambiental e os comportamentos de liderança que utilizam para promover o crescimento de suas organizações.

Não obstante referidos fatores limitantes, acredita-se que o estudo oferece contribuições para a Teoria da Administração e para as organizações em geral, especialmente quando os resultados apontam indícios que corroboram a literatura existente. Exemplos mais ilustrativos são: a) a aderência do perfil de liderança dos empreendedores ao modelo teórico de Yukl, Gordon e Taber (2002); b) o alinhamento entre as características psicológicas e comportamentais dos participantes e a perspectiva integracionista do comportamento empreendedor; c) a consonância entre a percepção dos participantes sobre as diferenças entre os papéis de líder e empreendedor e as conclusões dos estudos que envolvem o tema; d) a convergência entre prática comportamental dos empreendedores e proposição teórica sobre criação e transmissão de cultura organizacional; e e) a identidade entre a teoria de ciclo de evolução de organizações e o ambiente organizacional descrito pelos empreendedores. Podem ainda contribuir para os estudos em Administração os questionamentos sobre a eventual relação entre comportamentos de liderança, formação de cultura organizacional e autoimagem de líder.

\section{REFERÊNCIAS}

BASIT, T. Manual or electronic the role of coding in qualitative data. Educational Research, v. 45, n. 2, 2003 .

BURKE, W.; CHURCH, A. Managing change, leadership style, and intolerance to ambiguity: a survey of rganization development practitioners. Human Resource Management, v. 3I, n. 4, I992. CONGER, J.; KANUNGO, R. Toward a behavioral theory of charismatic leadership in organizational settings. Academy of Management. The Academy Management Review. v. I2, n. 4, I987.

CUFF, R. Notes for a panel on entrepreneurship in business history. Business History Review, v. 76 , n. I, 2002.

CUNNINGHAM, J; LISCHERON, J. Defining entrepreneurship. Journal of Small Business Management, v. 29, n. I, Jan. I99I.

CZARNIAWSKA-JOERGES, B.; WOLFF, R. Leaders, managers, entrepreneurs on and off the organizational stage. Organization Studies (Walter de Grupter GmbH \& Co. KG.), v. I2, n. 4, I99I. DALGLISH, C.; EVANS, P. Entrepreneurship versus leadership. In: INTERNATIONAL COUNCIL FOR SMALL BUSINESS, Brisbane, 2000. Proceedings...

DENZIN, N.; LINCOLN, Y. Handbook of qualitative research. Thousand Oaks: Sage Publications, 2000.

DRUCKER, P. Prefácio. In : HESSELBEIN, F.; GOLDSMITH, M.; BECKHARD, R. O líder do futuro. 9. ed. São Paulo: Futura, 200I. 
FAY, D.; LÜHRMANN, H. Current themes in organizational change. European Journal of Work \& Organizational Psychology, v. I3, n. 2, 2004.

FILION, L. From entrepreneurship to entreprenology. In: USASBE ANNUAL NATIONAL CONFERENCE - ENTREPRENEURSHIP: THE ENGINE OF GLOBAL ECONOMIC DEVELOPMENT, I997, San Francisco. Proceedings... Disponível em: <http://www.usasbe.org/knowledge/ proceedings/I997/p207Filion.pdf>. Acesso em: 6 jan. 2006.

FLICK, U. Uma introdução à pesquisa qualitativa. Porto Alegre: Bookman, 2004.

GARTNER, W. "Who is an entrepreneur?" is the wrong question. Entrepreneurship: Theory \& Practice, v. I3, n. 4, I988.

GODOY, A. Introdução à pesquisa qualitativa e suas possibilidades. RAE - Revista de Administração de Empresas, São Paulo, v. 35, n. 2, I995.

GOODMAN, P.; ROUSSEAU, D. Organizational change that produces results: The linkage approach. Academy of Management Executive, v. I8, n.3, 2004.

HANNAN, M.; PÓLOS, L.; CARROLL, G. Cascading Organizational Change. Organization Science: A Journal of the Institute of Management Sciences, v. I4, n. 5, 2003.

HESSELBEIN, F.; GOLDSMITH, M.; BECKHARD, R. O líder do futuro. 9. ed. São Paulo: Futura, $200 I$.

HILL, L. Charismatic leadership in organizations. Personnel Psychology, v. 52, n. 3, I999.

KETS DE VRIES, M. Liderança na empresa: como o comportamento dos líderes afeta a cultura interna. São Paulo: Atlas, I997.

KOTTER, J.; COHEN, D. The heart of change: real-life stories of how people change their organizations. Massachusetts: Harvard Business School Press, 2002.

KOUZES, J; POSNER, B. Sete lições para guiar a viagem para o futuro. In: HESSELBEIN, F.; GOLDSMITH, M.; BECKHARD, R. O líder do futuro. 9. ed. São Paulo: Futura, 20oI.

LOW, M.; MACMILLAN, I. Entrepreneurship: past research and future challenges. Journal of Management, v. I4, n. 2, I988.

MANN, S. Telling a life story: issues for research. Management Education and Development, v. 23, n. 3, I992.

MANZ, C. Self-leadership: toward an expanded theory of self-influence processes in organizations. Academy of Management Review, v. II, n. 3, I986.

MANZ, C.; BASTIEN, D.; HOSTAGER, T. Executive Leadership During Organizational Change: A Bi-Cycle Model. Human Resource Planning, v. I4, n. 4, I991.

MCCLELLAND, D. A sociedade competitiva: realização e progresso social. Rio de janeiro: Expressão e Cultura, I972.

MCLEAN, J. Management and Leadership. British Journal of Administrative Management. n. 49, 2005 .

NADLER, D.; TUSHMAN, M. Beyond the charismatic leader: leadership and organizational change. California Management Review, v. 32, n. 2, I990.

NECK, C. Thought self-leadership: a self-regulatory approach towards overcoming resistance to organizational change. International Journal of Organizational Analysis (1993-2002), v. 4, n. 2, I996.

PERREN, L. Comparing entrepreneurship and leadership - a textual analysis. The Council for Excellence in Management and Leadership, 2000. 
QUEIROZ, M. Variações sobre a técnica de gravador no registro da informação viva. São Paulo: T. A. Queiroz Editor, I99I.

SCHEIN, E. Organizational culture and leadership. San Francisco, CA: Sage, I992.

Liderança e cultura organizacional. In: HESSELBEIN, F.; GOLDSMITH, M.; BECKHARD, R. O líder do futuro. 9. ed. São Paulo: Futura, 200I.

SCHRUIJER, S.; VANSINA, L. Leadership and Organizational Change: An Introduction. European Journal of Work And Organizational Psychology, v. 8, n. I, I999.

SCHUMPETER, J. Teoria do desenvolvimento econômico: uma investigação sobre lucros, capital, crédito, juro e o ciclo econômico. 2. ed. São Paulo: Nova Cultural, I985.

STEINMETZ, L. Critical stages of small business growth. Business Horizons, v. I2, n. I, I969.

STEVENSON, H.; JARILLO, J. A paradigm of entrepreneurship: entrepreneurial management. Strategic Management Journal, v. II, n. 4, I990.

ULRICH, D.; ZENGER, J.; SMALLWOOD, N. Liderança orientada para resultados: como os líderes constroem empresas a aumentam a lucratividade. Rio de Janeiro: Campus, 2000.

YUKL, G.; GORDON, A.; TABER, T. A hierarchical taxonomy of leadership behavior: integrating a half century of behavior research. Journal of Leadership \& Organizational Studies, v. 9, n. I, 2002. 